\title{
c-type Lysozymes: what do their introns hide?
}

\author{
Pierre Jollès* \\ Molécules de Communication, Museum National d'Histoire Naturelle, 63 rue Buffon, F 75005 Paris, France \\ *Corresponding author's e-mail address: pierre.jolles@wanadoo.fr
}

Published online: October 8, 2014 (version 1)

Cite as: Jollés P., ScienceOpen Research 2014 (DOI: 10.14293/S2199-1006.1.SORLIFE.AJNDRN.v1)

Reviewing status: Please note that this article is under continuous review. For the current reviewing status and the latest referee's comments please click here or scan the QR code at the end of this article.

Primary discipline: Life sciences

Keywords: Lysozymes, Introns, Translation, Exons, Enzymes

\begin{abstract}
The introns of five c-type lysozymes were translated into amino acid sequences: parts of them corresponded to fragments of biologically active proteins. The amino acid sequences of translated introns seem to have a similar behavior as those arising from exons.
\end{abstract}

\section{INTRODUCTION}

Lysozyme (EC 3.2.1.17) is a ubiquitous enzyme. Several different types have been characterized, chicken (c-), goose (g-), phage-, invertebrate (i-), plant-, bacterial-types (for reviews, see [1]). The most studied lysozymes were the c-type enzymes and nearly 100 amino acid sequences have been established [2]. These enzymes share a high degree of similarity in their primary and tertiary structures. Their mechanism of action is very similar: they are considered to be involved in the antibacterial defense mechanism and in certain groups of mammals (ruminants, colobine monkeys) c-type lysozyme was recruited in the stomach and became a digestive enzyme [3].

Human lysozyme is synthesized in the secretory cells of a variety of exocrine glands and high concentrations were, as examples, detected in tears or mother's milk. The human lysozyme gene, its sequence organization and chromosomal localization have been described in detail by Peters et al. [4]. It is constituted by four exons and three introns. But other lysozyme genes have later been described as, for example, from hen (Gallus gallus) [5], rat (Rattus norvegicus) [6], cow (Bos taurus) [7], or pig (Sus scrofa) [8]. The present paper is devoted to their introns, more particularly to their amino acid sequences after translation which have so far not been studied.

\section{METHODS}

Translation and BLAST searches were performed according to Altschul et al. [9]. Hydrophobic cluster analysis (HCA) was achieved as described by Callebaut et al. [10].

\section{RESULTS AND DISCUSSION}

We were interested to investigate whether parts of lysozyme introns translated into amino acid sequences had closely related counterparts in biologically active, well-defined proteins: only longer sequences (30-45 amino acids) with $E$-values $<1$ e-01, identities higher than 55\% and satisfactorily HCA profiles were taken into consideration.

\section{Human lysozyme}

After translation, introns 1,2 , and 3 gave rise to peptide chains of 521, 646, and 284 amino acids, respectively. Only intron $1\left(5^{\prime} 3^{\prime}\right.$ frame 1 and frame 3$)$ and intron 3 (3'5' frame 2) had counterparts as defined above in various proteins. The presence of a Stop codon did not constitute an obstacle. Closely related fragments to translated intron 1 were present in human zinc finger protein (014628), human serine/ threonine-protein kinase Nek4 (P51957), human thromboxane A2 receptor (P21731), and human nitrogen-activated protein kinase 1 (096J02). Table 1 illustrates these data when translated intron 1 is considered.

Not only the sequences reported in Table 1 are related, but also the secondary structures as indicated in Figure 1 where HCA diagrams corresponding to closely related sequences (Table 1) are shown.

It should be emphasized that a high number of other translated lysozyme intron sequences with lower $E$-values but nevertheless significant identities could be characterized in various proteins. All the peptides described above were situated in the first half of the translated introns 1 and 3 where was located an Alu sequence. We were thus interested to extend the study to c-lysozymes of other origins.

\section{Cow-, hen-, pig-, and rat lysozymes}

The genes of the four lysozymes contain again three introns; however, the latter were devoid of an Alu sequence. This did 
Table 1. Comparison of translated human lysozyme intron $1,5^{\prime} 3^{\prime}$ frame 1 ( $A$ and $B$ ) and frame 3 (C and D) fragments (first line) with part of biologically active proteins (third line).

A) Human zinc finger protein ( $E=2$ e-08; Ident. $=74 \%$ )
$\begin{array}{ll}214 & \text { EMGFHHVGQAGLELLASNDLPTSASQSGRITGVNHCTQP } \\ 76 & \text { EMGFHH QA LELL S DLP SASQS ITGVNH QP } \\ & \text { EMGFHHATQACLELLGSSDLPASASQSAGITGVNHRAQP }\end{array}$

B) Human thromboxane $\mathrm{A} 2$ receptor $(E=3$ e-05; Ident. $=65 \%$ )

KTVSLCGPGWSAVA*SQLTATSAFWAQVILVLQPSE*L*LQ
VSLCGP WS VA S LTATSA Q ILV QP E L LQ
328 RRVSLCGPAWSTVARSRLTATSASRVQAILVPQPPEQLGLQ

C) Human serine/threonine-protein kinase NeK4 ( $E=1$ e- 07 ; Ident. $=67 \%$ )

D) Human mitogen-activated protein kinase kinase 1 ( $E=7$ e-05; Ident. $=69 \%)$

The numbers indicate the location of the fragment in the translated intron or in the protein.

${ }^{*}$ Corresponds to a Stop codon.
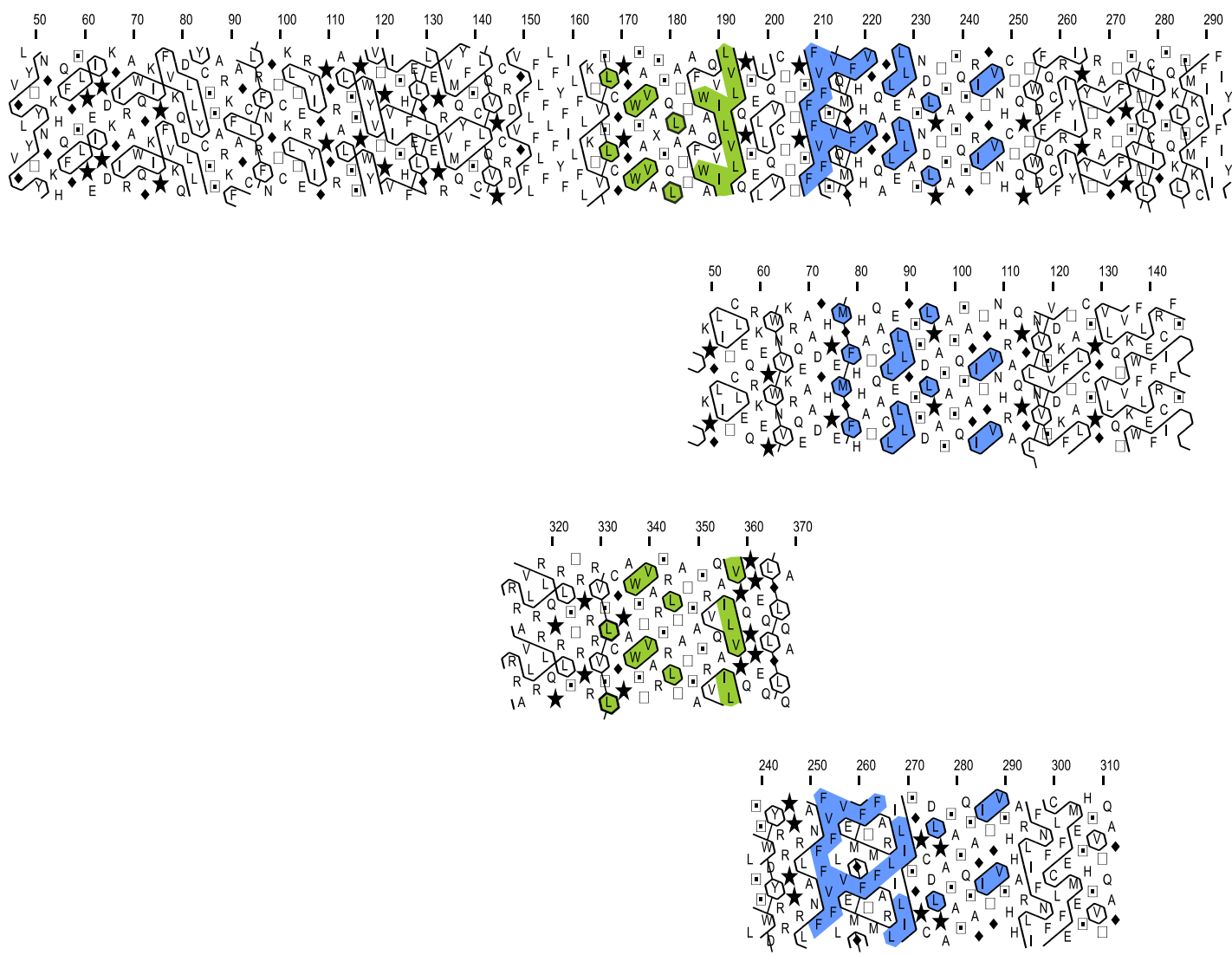

Figure 1. Hydrophobic cluster analysis of (a) human lysozyme intron 1, 5'3' frame 1 (only amino acids 50-300 are visualized); (b) zinc finger protein: residues 76-114 correspond to residues 210-248 of the intron ( $E=6$ e-08; identity: 76\%); (c) human thromboxane A2 receptor: residues 328-368 correspond to residues 160-200 in the intron ( $E=7$ e-06; identity: $69 \%$ ); (d) human neuronal thread protein: residues $252-319$ correspond to residues $210-277$ of the intron ( $E=0.042$; identity: $54 \%$ ). 
Table 2. Comparison of two translated rat intron and one translated pig intron lysozyme sequences with fragments of biologically active proteins. (For further details, see legend to Table 1.)

Rat lysoyme, intron 2, 5'3' frame 3 compared to ubiquitin-protein ligase Nedd-4 ( $E=4$ e-05; Ident. = 48\%)

QGSRAPGTGVTDSCELPCGCWESTPL-EEHPVLLASELLSS

Rat lysozyme, intron $3,3^{\prime} 5^{\prime}$ frame 1 compared to tumor necrosis factor ligand superfamily member $13 B$ (B-cell activating factor) $(E=0.003 ;$ Ident $=75 \%)$

39

134

\author{
SDEDVELSAPPAPCLPGCCH \\ DV LSAPPAPCLPGC $\mathrm{H}$ \\ TEQDVDLSAPPAPCLPGCRH
}

58

153

Pig lysozyme, intron $1,5^{\prime} 3^{\prime}$ frame 3 compared to major surface antigen precursor $(E=4.1$; Ident. $=50 \%)$

506

KFSW-SCSVPMAQWFKNLTPVAWVTA

FSW S VP QWF L P W A

RFSWLSLLVPFVQWFVGLSPTVWLSA
531 not prevent that after translation, but to a lesser extent, some sequences, generally shorter than in the case of human introns, corresponded to sequences contained in well-defined biologically active proteins: the identities were again around $60 \%$ but with more variable $E$-values. Some examples are quoted in Table 2.

\section{CONCLUSION}

The present data constitute a contribution to studies devoted to the amino acid sequences of translated introns. These sequences seem to have a similar behavior as those corresponding to exons when the occurrence of the different amino acids (hydrophilic and hydrophobic) as well as the secondary structures are considered. They demonstrate also that these intron sequences contain a high number of short but in some cases also long sequences corresponding to the parts of biologically active proteins.

\section{REFERENCES}

[1] Jollès P., ed. Lysozymes, model enzymes in Biochemistry and Biology. Basel: Birkhäuser Verlag; 1996. 454 p.

[2] Prager E, Jollès P. Animal lysozymes c and g: an overview, in Lysozymes, model enzymes in Biochemistry and Biology. Basel: Birkhäuser Verlag; 1996. pp. 9-31.

[3] Stewart C-B, Schilling JW, Wilson AC. Adaptive evolution in the stomach lysozymes of foregut fermenters. Nature. 1987;330 (6146):401-4. doi:10.1038/330401a0

[4] Peters CWP, Kruse U, Pollwein R, Grzeschik K-H, Sippel AE. The human lysozyme gene: sequence organization and chromosomal localization. Eur J Biochem. 1989;182(3):507-16. doi:10.1111/ j.1432-1033.1989.tb14857.x

[5] Jung A, Sippel AE, Grez M, Schütz G. Exons encode functional and structural units of chicken lysozyme. Proc Natl Acad Sci USA. 1980;77(10):5759-63. doi:10.1073/pnas.77.10.5759

[6] Yeh TC, Wilson AC, Irwin DM. Evolution of rodent lysozymes: isolation and sequence of the rat lysozyme genes. Mol Phylogenet Evol. 1993;2(1):65-75. doi:10.1006/mpev.1993. 1007
[7] Irwin DM, White RT, Wilson AC. Characterization of the cow stomach lysozyme genes: repetitive DNA and concerted evolution. J Mol Evol. 1995;41(3):299-312. doi:10.1007/BF0121 5177

[8] Yu M, Irwin DM. Evolution of stomach lysozyme: the pig lysozyme gene. Mol Phylogenet Evol. 1996;5(2):298-308. doi:10.1006/mpev.1996.0025

[9] Altschul SF, Madden TL, Schaffer AA, Zhang J, Zhang Z, Miller W, Lipman DJ. Gapped BLAST and PSI-BLAST: a new generation of protein database search programs. Nucleic Acids Res. 1997;25 (17):389-402. doi:10.1093/nar/25.17.3389

[10] Callebaut I, Labesse G, Durand P, Poupon A, Canard L, Chomilier J, Henrissat, B, Mornon J-P. Deciphering protein sequence information through hydrophobic cluster analysis (HCA): current status and perspectives. Cell Mol Life Sci. 1997;53(8):62145. doi:10.1007/s000180050082

\section{COMPETING INTERESTS}

The author declare no competing interests.

\section{PUBLISHING NOTES}

(C) 2014 Pierre Jollès. This work has been published open access under Creative Commons Attribution License CC BY $\underline{\mathbf{4 . 0}}$, which permits unrestricted use, distribution, and reproduction in any medium, provided the original work is properly cited. Conditions, terms of use and publishing policy can be found at www.scienceopen.com.

Please note that this article may not have been peer reviewed yet and is under continuous post-publication peer review. For the current reviewing status please click here or scan the QR code on the right.

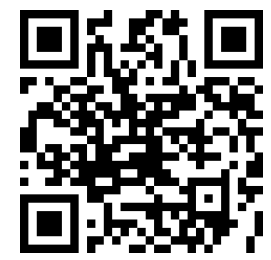

